\title{
Hand foot syndrome associated with docetaxel treatment in metastatic prostate cancer: A case report
}

\section{Dosetaksel tedavisi ile iliş̧ili EI Ayak Sendromu gelişen metastatik prostat kanserli bir hasta}

\author{
Erdem Şen, İrem Öner, Özlem Ata
}

Selçuk Üniversitesi Tıp Fakültesi, İç Hastalıkları Ana Bilim Dalı, Tıbbi Onkoloji Bilim Dalı, Konya

Dergiye Ulaşma Tarihi: 24.05.2017 Dergiye Kabul Tarihi: 18.08.2017 Doi: 10.5505/aot.2017.58671

\section{ÖZET}

Prostat kanseri erkeklerde en yaygın görülen tümörlerden biridir. Dosetaksel ve prednison tedavisi prostat kanserli hastalarda standart kemoterapi tedavisi olarak kabul edilmektedir. Dosetaksel tübülin depolimerizasyonunu engelleyerek, mikrotübüllerin stabilizasyonu yoluyla antitümöral etki gösteren taksan grubu kemoterapötik ilaçtır. Dosetaksel tedavisinin sistemik yan etkilerinin yanında kutanöz yan etkilere yol açtığı da bildirilmiştir. Dosetaksel kullanımı ile en sık görülen kutanöz yan etkiler alopesi, el ayak sendromu, fiks plak eritrodizestezisi, tırnak değişiklikleridir. El ayak sendromu el ve ayaklarda bilateral, simetrik yerleşim gösteren eritemden, deskuamasyon gösteren ödemli plaklara kadar değişen klinik tablolarla karşımıza çıkabilir. El ayak sendromu kemoterapi tedavisinin ilerleyen hafta veya aylarında ortaya çıktığı bildirilmiştir. Biz metastatik prostat kanserli hastalarda sık kullanılan dosetaksel kemoterapi tedavisi ile ilişkili el ayak sendromu gelişen olgumuzu sunduk.

Anahtar Kelimeler: Prostat Kanseri, El ayak sendromu, Dosetaksel

\begin{abstract}
Prostate cancer is one of the most common tumors in men. Docetaxel and prednisone treatment are accepted as standard chemotherapy in prostate cancer patients. Docetaxel is a chemotherapeutic drug of the taxane group that inhibits the depolymerization of tubulin and has an antitumoral effect through the stabilization of microtubules. It has also been reported that docetaxel therapy lead to cutaneous side effects besides systemic side effects. The most common cutaneous side effects of docetaxel are alopecia, hand foot syndrome, fixed plaque erythrodysesthesia, nail changes. Hand foot syndrome can be confronted with clinical tables ranging from bilateral, symmetrical erythema to desquamated plaques on hands and feet. It has been reported that hand foot syndrome occurred in the following weeks or months of chemotherapy treatment. We would like to present our case of hand foot syndrome associated with docetaxel chemotherapy treatment which is commonly used in patients with metastatic prostate cancer.
\end{abstract}

Keywords: Prostate cancer, Hand foot syndrome, Docetaxel

\section{Giriș}

Prostat kanseri erkeklerde en yaygın görülen tümörlerden biridir (1). Metastatik prostat adenokanserli hastaların tedavisinde kastrasyon amaçlı androjen deprivasyon tedavisi (ADT) önemli yer tutmaktadır. ADT ile kastrasyona rağmen prostat kanserinde progresyon görülmektedir ve kastrasyona dirençli prostat kanseri (KDPK) olarak tanımlanmaktadır. 3 haftal1k dosetaksel ve prednison tedavisi KDPK hastalarında standart tedavi olarak kabul edilmektedir (2). Dosetaksel ve prednison tedavisi aynı zamanda kastrasyon sensitif, tümör volümü yüksek, metastatik prostat kanserli hastalarda da ADT ile beraber standart tedavi haline gelmiştir. Dosetaksel tübülin depolimerizasyonunu engelleyerek, mikrotübüllerin stabilizasyonu yoluyla antitümöral etki gösteren taksan grubu kemoterapötik ilaçtır. Dosetaksel tedavisi ile nötropeni, sıv1 retansiyonu, hipersensitivite reaksiyonları, periferik nöropati gibi sistemik yan etkiler görülmektedir. Ciltte görülen yan etkiler çok çeşitli olmakla beraber fotosensitivite, infüzyon bölgesi reaksiyonlar1, alopesi, tırnak değişiklikleri, el-ayak sendromu (EAS), lupus benzeri döküntü ve radyasyon geri 
çağırma (recall) fenomeni şeklinde görülebilmektedir (3). Biz bu çalışmamızda KDPK tedavisinde sık olarak kullandığımız dosetaksel tedavisine bağlı bilateral el dorsal yüzlerde daha belirgin görülen, EAS gelişen olgumuzu sunduk.

\section{Olgu Sunumu}

66 yaşında erkek hastaya dış merkez üroloji bölümünde prostat adenokarsinomu tanısı konulmuş definitif radyoterapi ve ADT tedavisi verilmiştir. 2 yıl ADT tedavisi sonrası izleme alınan hastada, izlem sürecinin 2. yılında prostat spesifik antijen (PSA) artış1 saptanmıştır. ADT tekrar başlanan hasta tedavisinin 7. ayında PSA progresif artmas1 nedeni ile kliniğimize başvurdu. Evreleme tetkiklerinde kemik metastazları saptandı. Total Testosteron kastre düzeyde idi. KDPK kabul edilen hastaya ADT tedavisine ilaveten zoledronik asit ve 3 haftada bir dosetakselprednisolon tedavisi( $75 \mathrm{mg} / \mathrm{m} 2: 720 \mathrm{mg}$ toplam doz) başlandi. Biyokimyasal yanıtı olan hastada 6. kür sonunda bilateral el dorsal yüzlerde daha belirgin olmak üzere el palmar ve dorsal yüzlerde eritemli, skuaml, hafif ödemli cilt lezyonları gelişti. Kseroderma mevcuttu. Grade 2 EAS olarak kabul edildi. Özellikle el tırnaklarında distrofik değişiklikler vardı (Resim 1,2,3,4,5). Dosetaksel tedavisi kesilerek, dermatolojik tedavisi açısından nemlendirici krem, topikal steroid uygulandi.

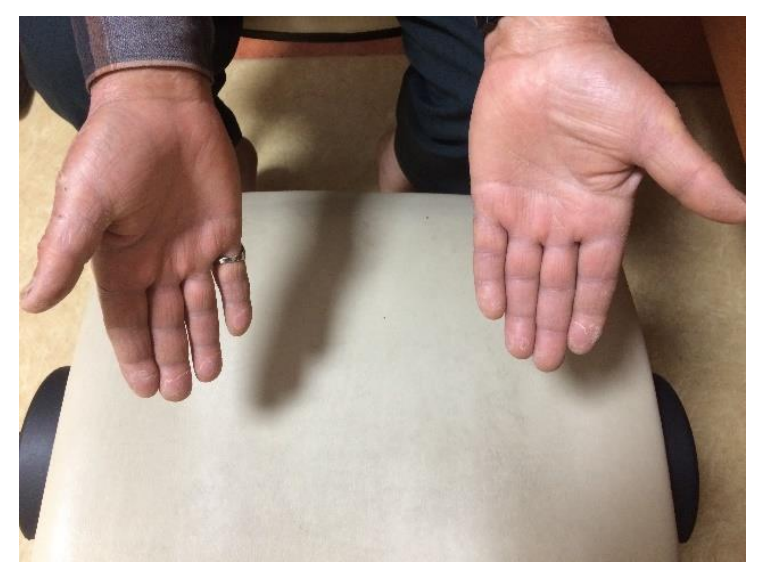

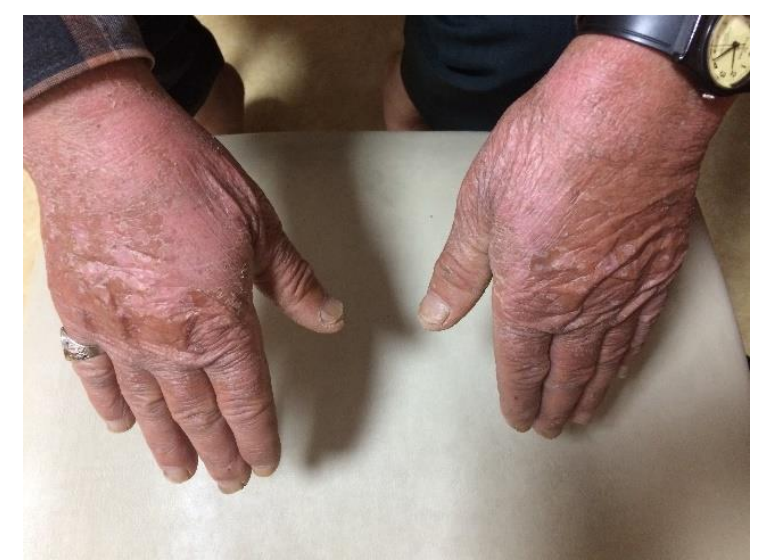

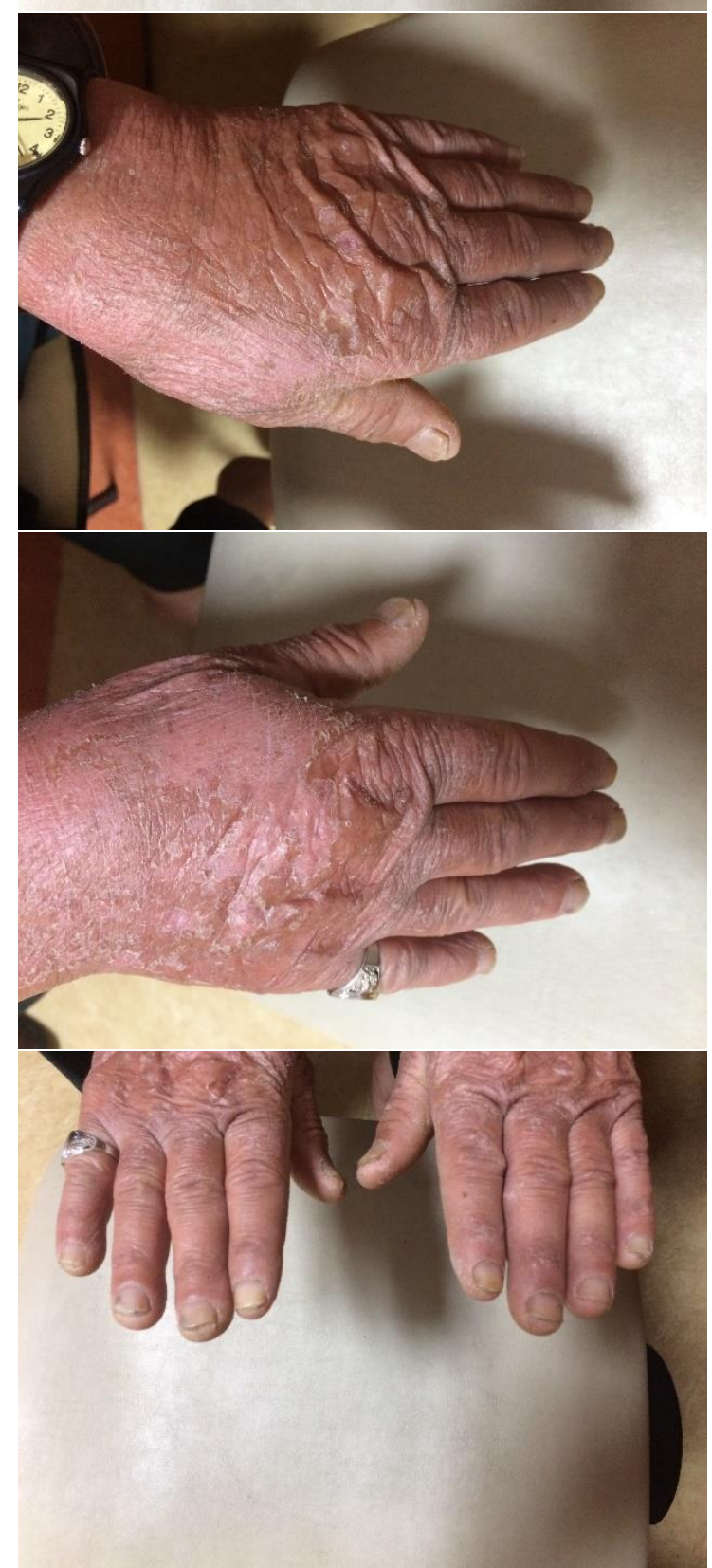

Resim: Dosetaksel tedavisinin 6. Kürü sonrasinda ortaya çıkan özellikle el dorsal yüzü etkileyen bilateral El ayak sendromu. Kseroderma mevcut. Eritemli, squamlı,hafif ödemli lezyonlar 
görülmektedir. El tırnaklarında distrofik değişiklikler mevcuttur.

\section{Tartışma}

EAS el ve ayaklarda bilateral, simetrik yerleşim gösteren eritemden, deskuamasyon gösteren ödemli plaklara kadar değişen klinik tablolarla karşımıza çıkabilir. Dosetakselin tek başına kemoterapi tedavisi olarak verildiğinde EAS insidans $1 \% 1$ ve altında olduğu bildirilmiştir (4). Genellikle avuç içi ve ayak tabanlarında görülmekle beraber el veya ayak sırtında da lezyonlar görülebilmektedir. Kontakt dermatit, el dorsal yüze ilaç uygulama öyküsü olmayan hastamızda EAS bilateral el dorsal yüzde belirgindi. EAS başlangıç zamanı değişmekle beraber genellikle kemoterapi tedavisinin ilerleyen hafta veya aylarında ortaya çıkmaktadır. Genellikle haftalık dosetaksel uygulaması ile EAS görülürken olgumuzda bu toksisite 3 haftalık uygulamada görülmüştür. EAS Gelişen hastada tedavide topikal keratolitikler, antibiyotikler, analjezikler, antiseptikler kullanılabilinir. Ayrıca EAS gelişimine koruyucu olarak nemlendirici kremler, üre içerikli losyonlar kullanılabilir. Hastaların sıcak su, alkol içerikli solüsyonlardan, sık1 ayakkabılardan uzak durmas1 gerekmektedir. Choukri Elm'hadi ve arkadaşlarının yapmış olduğu 2016 yılında yayımlanan bir çalışmada 81 vakada orijinal dosetaksel ve 3 ayrı dosetaksel muadili ilaç toksisiteleri açısından karşılaştırılmıştır. Bu çalışamaya göre cilt toksisiteleri (özellikle grade 3), tırnak değişiklikleri, anormal cilt toksisiteleri (orijinal ilaçta hiç görülmeyen) dosetaksel muadili ilaçlarda orijinal ilaca göre daha fazla görüldügü bildirilmiştir (5). Bizim hastamızda da muadil ilaç kullanımı olmuştur.

Olgumuz, EAS'in her zaman palmoplantar bölge ile sinırlı kalmadığını gösteren bir örnektir. Haftalık dosetaksel tedavisi ile daha sıklıkla görülen EAS olgumuzda olduğu gibi 3 haftalık rejim ile de görülebilmektedir. Orijinal ilaçlarda az veya hiç görülmeyen toksisitelerin muadil ilaçlar ile daha fazla görülmesi, ülkemizdeki mevcut durumlar nedeni ile ilerleyen zamanda karşımıza sik olarak çıkabileceğini düşünmekteyiz.
Finansal destek: Yazarlar finansal destek almadığını bildirmişlerdir.

\section{Referanslar}

1. Jemal A,Bray F,Centre MM, Ferlay J,Ward E, Forman D. Global cancer statistics. CA Cancer J Clin 2011;61 (2):69-90.

2. Tannock IF, de Wit R, Berry WR,Gorti J,Pluzanska A, Chi KN, et al. Docetaxel plus prednisone or mitoxantrone plus prednisone for advanced prostate cancer. N Engl J Med 2004;351 (15):1502-12.

3. Chew L, Chuen VS. Cutaneous reaction associated with weekly docetaxel administration. J Oncol Pharm Pract 2009; 15 (1):29-34.

4. Farhat HM, Nagi S, Saghir EL. Hand foot syndrome with docetaxel: a five case series. Ann Saudi Med 2008; 28 (5): 374-7.

5. Choukri Elm'hadi, Rachid Tanz, Mohamed Reda Khmamouche, Mehdi Toreis, Tarik Mahfoud, Khaoula Alaoui Slimani et al. Toxicities of docetaxel: original drug versus generics - a comparative study about 81 cases. Springer Plus 2016; 5:732. 